\title{
Teaching with High-Cognitive- Demand Mathematical Tasks Helps Students Learn to Think Mathematically
}

Jeremy F. Strayer and Elizabeth Brown

A recent Doceamus article in the Notices (Sweller, Clark, and Kirschner, 2010) argued that having students study worked examples of problem types rather than actually solving problems is the preferable way to teach mathematics. The article cited a study (Sweller and Cooper, 1985) that compared one group of students who solved multiple routine algebra problems with another group who studied worked examples of similar problem types. Their analysis showed that the worked-examples group outperformed the problem-solving group. To further make their case against problem solving, the authors critiqued Pólya and claimed that: (1) teaching only general problem-solving skills and (2) providing minimal instructional guidance to students does not lead to successful mathematics learning.

We agree with Sweller, Clark, and Kirschner that it is indeed misguided to use repeated routine problem solving as the primary means of mathematics instruction. We further agree that it is not preferable to base one's mathematics instruction on the above two criteria. However, we contend that the current vision and practice of the mathematics community that has been influenced

Jeremy F. Strayer is assistant professor of mathematics at Middle Tennessee State University. His email address is Jeremy. Strayer@mtsu . edu.

Elizabeth Brown is associate professor of mathematics and computer science at Indiana State University. Her email address is Liz. Brown@ indstate.edu.

Members of the Editorial Board for Doceamus are: David Bressoud, Roger Howe, Karen King, William McCallum, and Mark Saul.

DOI: $10.1090 /$ noti786 by Pólya's ideas do not draw primarily on routine problem solving. Neither do they rely heavily on the two criteria outlined above. Thus the case that Sweller, Clark, and Kirschner (2010) make against problem solving in mathematics classrooms misses the point.

In this article, we provide a brief description of the progression of research into problem solving in mathematics classrooms over the last few decades and describe one way this research has led to productive mathematics teaching and learning in our classrooms.

Pólya's recommendation that teachers overtly teach problem-solving strategies was novel and indeed quite radical when first presented (Passmore, 2007). It should be noted that Pólya's aim was not to teach problem solving for problem solving's sake. Rather, it was to help students learn to think the way mathematicians think when they do mathematics (Pólya, 1945, 1954). Problem solving for mathematicians entails employing one's energies and talents to solve nonroutine, perplexing, and difficult mathematics problems (Schoenfeld, 1992). Influenced by Pólya's ideas, the mathematics education community embraced teaching mathematics through problem-solving tasks that develop conceptual understanding-without relying on traditional drill-and-practice routines. Does this way of teaching work? A recent meta-analysis of 109 independent experiments (both quasi- and randomized experimental designs) provides strong empirical support for the claim that teaching mathematics conceptually improves student achievement (Rakes, Valentine, McGatha, and Ronau, 2010).

As one can imagine, conducting research into mathematics instruction that is conceptually focused is multifaceted and quite complex. One line of research that we have found particularly interesting and useful in our classrooms focuses on the nature of the 
mathematical problems (or tasks) that students complete and what occurs in the classroom when these tasks are implemented. Stein, Smith, Henningsen, and Silver's (2009) research-based Task Analysis Guide (TAG) provides a helpful four-tier classification of classroom tasks. The first two task types are low in cognitive demand. Memorization tasks require students to commit to memory and/or recall previously learned definitions, facts, rules, or other mathematical knowledge. Procedures without connections to underlying mathematical concepts tasks focus on the procedure required to get the correct answer to the given problem with no connection to the underlying concepts or mathematical meaning in the task. The next two task types are high in cognitive demand. Procedures with connections to underlying mathematical concepts tasks do imply the use of a specific procedure to complete the task, but the purpose for the use of the procedure is to foster deeper levels of understanding of the mathematical concepts underlying the task. To accomplish this conceptual connection, these tasks often rely on multiple representations of the problem (e.g., graphical, verbal, analytic) and require significant cognitive effort to complete. Doing mathematics tasks presents students with a nonroutine mathematics problem that does not hint at a predictable pathway toward a solution in the task itself, the instructions, or a worked-example solution. This kind of task requires students to explore mathematical concepts, analyze the task to understand the structure of possible solutions, make use of existing mathematical knowledge, and regulate their own cognitive processes as they work through the task.

The majority of tasks completed in mathematics classrooms across the United States (as well as the tasks referenced in the aforementioned Doceamus article) are low-cognitive-demand tasks of the first two types in the TAG. Although there is a place for all types of mathematical tasks depending on the learning goals of the lessons, research into the instructional differences that exist between countries in which students perform highly in mathematics versus countries in which students perform at lower levels, such as the United States, shows that the higher performing countries provide students opportunities for prolonged engagement with mathematical tasks at a high cognitive level (Stigler and Hiebert, 2004).

It is a challenge to provide college students with opportunities for prolonged engagement with mathematical tasks at a high cognitive level, something many of our students have never been asked to do. Nevertheless, we believe it is crucial to give students an opportunity to engage in tasks in this way, particularly if some of these students will be future mathematics teachers. Here, we describe our efforts to accomplish this in a portion of the Analytic Geometry course we teach for mathematics and mathematics education majors. We begin the course with a series of routine low-cognitivedemand review activities that ask students to plot points, find the distance between points, find equations for lines, and so forth. Then we challenge students to develop mathematical habits of mind through the sustained use of sequenced high-cognitive-demand tasks in the following way. First, we define the Euclidean and taxicab metrics as

$$
\begin{aligned}
& d_{E}=\sqrt{\left(x_{2}-x_{1}\right)^{2}+\left(y_{2}-y_{1}\right)^{2}} \text { and } \\
& d_{T}=\left|x_{2}-x_{1}\right|+\left|y_{2}-y_{1}\right|, \text { respectively. }
\end{aligned}
$$

Next, we present students with tasks that ask them to graph circles with various centers $A$ and radii $r$ using the locus of points definition of a circle $\{P \mid d(P, A)=r\}$ using both metrics. As students complete these tasks relying strictly on the definition of distance, they are confronted with the counterintuitive task of graphing taxi circles, which are shaped like squares. Once students are comfortable with creating circles, the next set of tasks requires students to use circles as tools to find particular loci, such as $\{P \mid d(P, A)=d(P, B)\}$ and $\{P \mid d(P, A)+d(P, B)=2 a\}$. In the Euclidean case, these loci are the perpendicular bisector of a segment and an ellipse, respectively. The idea of using circles and intersections of circles as a tool to find a locus of points is new to students, and they require time to struggle with the concept. It is crucial that students are pushed to express their thinking and engage in meaningful student-student and student-teacher discourse for these tasks to be successful in supporting learning.

We use Texas Instruments nspire technology to help students investigate and complete the above tasks. At first, the circles get in the way, and it is our experience that students feel lost in the details. But, as both teacher and student press each other to make sense of the task and justify reasoning, students learn at deep levels. Figure 1 and Figure 2 show student work in creating the locus of points equidistant to $(0,0)$ and $(6,2)$ using both metrics. Figure 3 and Figure 4 show ellipses in both metrics

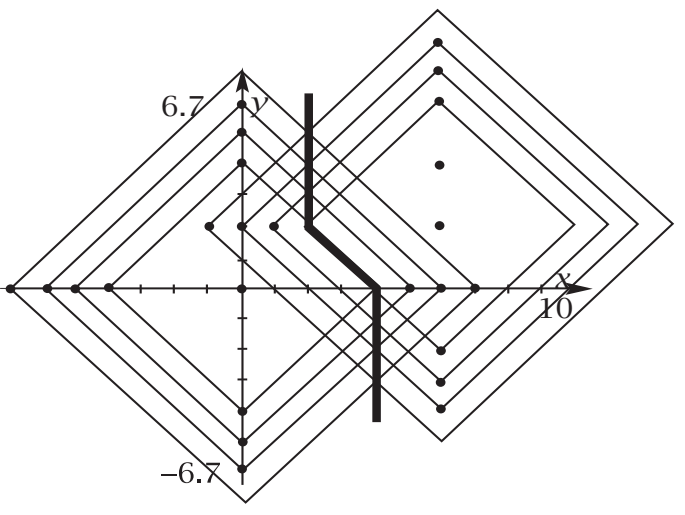

Figure 1. 


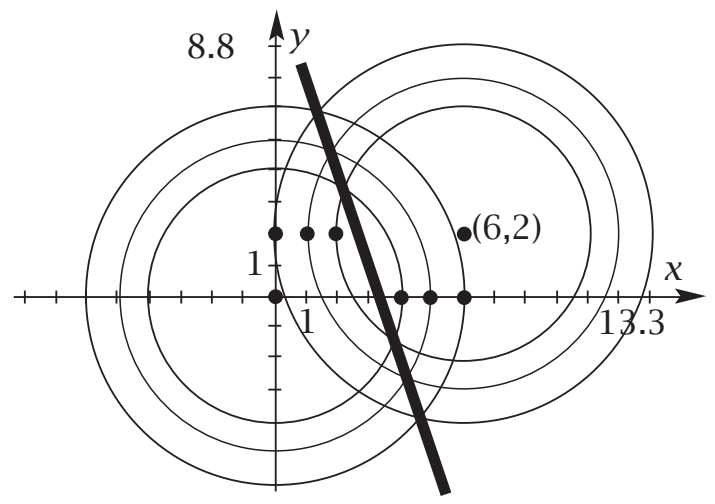

Figure 2

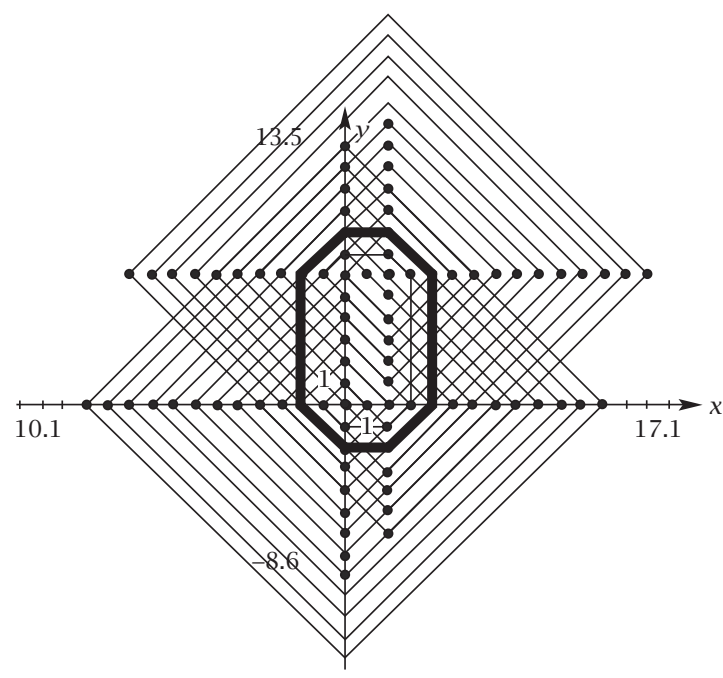

Figure 3

with focal distance 8 and $2 a=12$. Students complete other examples and are confronted by the fact that these loci have varying properties when using $d_{T}$ that depend on the relative locations of the points $A$ and $B$ (try a few examples to investigate!), while they behave more consistently under $d_{E}$.

Implementing the above tasks can be quite messy at times. However, if we, as the instructors, build on prior student knowledge, support student thinking as they complete the task, require students to justify and explain their work, and repeatedly make explicit conceptual ties to student work, then the tasks are likely to support high-level cognitive engagement with mathematical ideas (Stein et al., 2009). Conversely, if we give in to student pressure to show them the steps to go through to solve the problem, shift the focus to the correct answer rather than the mathematical meaning and concepts, or give credit for low-level work on the task, then the task will likely decline into low-level engagement with mathematical ideas. Further, we have found that if we press for high-level engagement with the above tasks, then students are better able to make sense of the

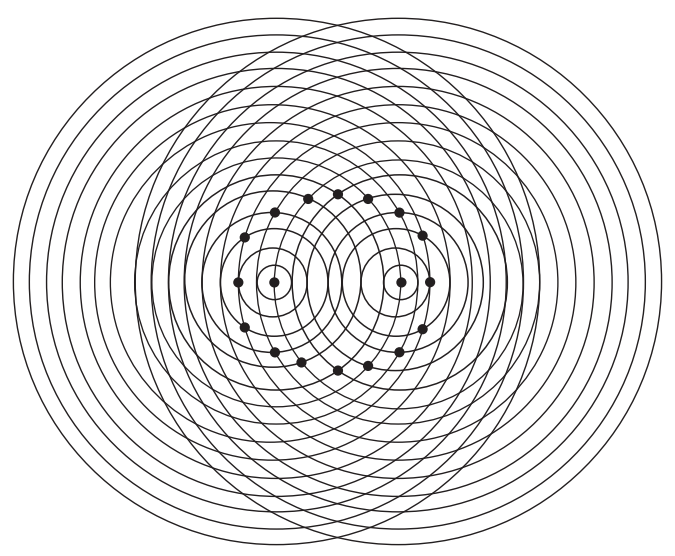

Figure 4

connections between various definitions of conic sections later in the course.

Pólya's objective over a half century ago to focus mathematics instruction on introducing students to the intellectual rewards acquired through problem solving has inspired mathematicians and mathematics educators the world over to create instructional strategies aimed at accomplishing this goal. When we engage students with domainspecific tasks at a high cognitive level, we are well on our way to meeting this challenge, and our students are better positioned to make sense of lines of mathematical reasoning.

\section{References}

T. PASSMORE, Polya's legacy: Fully forgotten or getting a new perspective in theory and practice?, Australian Senior Mathematics Journal 21 (2007), 44-53.

G. PÓLyA, How to Solve It, Princeton University Press, Princeton, New Jersey, 1945 (2nd ed., 1957).

, Mathematics and plausible reasoning: Volume 1, Induction and Analogy in Mathematics; Volume 2, Patterns of Plausible Inference, Princeton University Press, Princeton, New Jersey, 1954.

C. R. Rakes, J. C. VAlentine, M. B. McGatha, and R. N. RONAU, Methods of instructional improvement in algebra: A systematic review and meta-analysis, Review of Educational Research 80 (2010), 372-400.

A. H. SCHOENFIELD, Learning to think mathematically: Problem solving, metacognition, and sense-making in mathematics, in Handbook for Research on Mathematics Teaching and Learning, (D. Grouws, ed.), MacMillan, New York, 1992, 334-370.

M. K. Stein, M. S. Smith, M. A. Henningsen, and E. A. SILVER, Implementing Standards-Based Mathematics Instruction: A Casebook for Professional Development (2nd ed.), Teachers College Press, New York, 2009.

J. W. STIGLER and J. Hiebert, Improving mathematics teaching, Educational Leadership 61 (2004), 12-16.

J. SWELLER, R. ClARK, and P. KiRSCHNER, Teaching general problem-solving skills is not a substitute for, or a viable addition to, teaching mathematics, Notices of the AMS 57 (2010), 1303-1304.

J. SwELLER and G. COOPER, The use of worked examples as a substitute for problem solving in learning algebra, Cognition and Instruction 2 (1985), 59-89. 